\title{
GNATHANTHIDIUM, GEN.N. DE ANTHIDIINAE DA AMÉRICA DO SUL (HYMENOPTERA, MEGACHILIDAE) ${ }^{1}$
}

\author{
Danúncia Urban ${ }^{2}$
}

\begin{abstract}
GNATHANTHIDIUM, GEN.N. OF ANTHIDIINAE FROM SOUTH AMERICA (HYMENOPTERA, MEGACHILIDAE). Gnathanthidium, gen.n. is proposed for two new species from South America, one from Brazil (Paraná, Santa Catarina and Rio Grande do Sul) and Argentina (Misiones) Gnathanthidium sakagamii, sp.n. and another from Argentina (Tucuman) Gnathanthidium ferrugineum, sp.n. The female of this Anthidiine bee has peculiar mandibles without large teeth, only with two little ones on the apical margin.
\end{abstract}

Key words. Gnathanthidium, gen.n., Anthidiinae, Megachilidae, taxonomy

Gnathanthidium, gen.n. de Dianthidiini é proposto para duas espécies novas, uma do sul do Brasil e Argentina (Misiones) Gnathanthidium sakagamii, sp.n. e outra da Argentina (Tucumán) Gnathanthidium ferrugineum, sp.n., cujas principais características são: carenas interalveolares fortes e arqueadas cobrindo parte dos alvéolos, porém não elevadas; redução das carenas mandíbulares; escutelo com projeções laminares laterais porém reto no bordo posterior. As fêmeas com mandibulas quase lisas no bordo cortante, apenas com dois pequenos dentes no ápice externo, e cerdas de ápice em gancho nas genas ou nas peças bucais. Os machos com o sétimo tergo com recorte raso orlado por duas projeções dentiformes e alargando muito para a base, ápice do sexto tergo com projeção laminar reta. A ausência de dentes ao longo da margem cortante das mandíbulas da fêmea foi observada por MOURE (1965) ao propor Adanthidium como gênero novo para Anthidium texanum Cresson, 1878, com um dente apical porém com carena lateral externa na mandíbula e carenas inferiores alcançando a metade da mandíbula; e por MICHENER (1988), no sub-gênero Deranchanthidium proposto para Dianthidium Cockerell, 1900 incluindo duas espécies que ocorrem no México (com carena pré-ocipital forte dorsalmente e carena transversal no mesoscuto anteriormente, porém sem arólios e sem carenas interalveolares).

1) Contribuição número 777 do Departamento de Zoologia, Universidade Federal do Paraná.

2) Departamento de Zoologia, Universidade Federal do Paraná, Caixa Postal 19020, 81531-970 Curitiba, Paraná, Brasil. 


\section{Gnathanthidium, gen.n.}

Espécie tipo: Gnathanthidium sakagamii, sp.n.

Macho. Tegumento brilhante, densamente marcado por pontos grandes. Mandíbulas tridentadas com dois dentes apicais grandes externos muito próximos, porém separados do dente basal por amplo recorte circular; sem carena lateral externa ao longo da mandíbula, com duas carenas muito curtas no lado externo do dente apical, a inferior formando uma angulosidade subapical e uma terceira carena (interna-inferior) também partindo do dente apical e até o meio da mandíbula, porém só visível posteriormente; tegumento densamente micropontuado excetuando nos dentes apicais. Palpos maxilares com dois artículos, o basal reduzido e com pequeno tubérculo projetado para a base e o apical muito longo e achatado, com pêlos curtos. Clípeo abaulado, deprimido no ápice sem tubérculos na margem apical, porém com o contorno fracamente emarginado no meio e nos lados, sobrepassando a base do labro; suturas subantenais quase retas; carenas interalveolares fortes e laminadas, a lâmina projetada em arco sobre o bordo interno do alvéolo antenal, tão afastadas na área supraclipeal quanto seu comprimento; sem carena frontal; carenas paroculares na parte inferior e na mediana; genas estreitas, diminuindo em direção às mandíbulas; carena hipostomal forte; sem carena pré-ocipital; antenas com escapo mais longo que a distância interalveolar e os flagelômeros mais curtos que seu diâmetro.

Pronoto com lamela curta nos lobos, terminando em ângulo ventralmente e arqueada em direção ao mesoscuto no lado dorsal, terminando antes da sutura; mesepisternos com carena pré-episternal na metade superior; mesoscuto expandido lateralmente em lâmina voltada para cima; escutelo quase reto posteriormente, expandido em lamela aos lados e sobressaindo ao metanoto; mesoscuto, escutelo e axilas quase num mesmo plano; base do escutelo deprimida e brilhante entre as axilas, não dividida; axilas projetadas para trás porém não carenadas; tégulas arredondadas posteriormente, sem emarginação subapical interna; asas anteriores com a bifurcação entre a média e a cubital coincidindo com a transversal cúbito-anal; asas posteriores com lobo jugal aproximadamente um terço do lobo anal; tarsômeros com pilosidade curta, sem formar franja; com arólio entre as garras. Propódeo vertical, com fovéolas látero-basais; espiráculo propodeal carenado com larga área posterior brilhante fracamente foveolada.

Tergos com depressão marginal estreita nos flancos do segundo ao sexto, este quase vertical com projeção apical laminada reta e dois pequenos dentes subapicais bem laterais; sétimo tergo voltado para a frente, com recorte raso no meio, levemente bi-sinuoso orlado com duas projeções dentiformes e alargando muito para a base, com larga área ventral; esternos normais, com pilosidade curta, mais longa nos flancos; esterno basal com carena laminada no meio dos dois terços basais e subapicalmente inflado; sexto esterno com o bordo reto.

Fêmea. Semelhante ao macho. Difere nas seguintes estruturas: man- 
díbula com o bordo apical liso, muito largo e quase inteiramente reto, em ângulo na base e com dois pequenos dentes distais, o subapical muito pequeno e o apical com duas carenas curtas, sem carena na margem inferior; primeiro ao quinto tergos com depressão marginal estreita nos flancos; sexto tergo sem carena mediana, um pouco deprimido no disco e elevado para o ápice; sexto esterno normal; pernas com pilosidade curta, lado externo da tíbia mediana com projeção espiniforme apical; trocânter posterior com carena laminada na metade apical do bordo posterior; arólio rudimentar entre as garras; palpo maxilar como no macho, porém com cerdas longas de ápice em gancho, divergentes e só na área basal, no restante cerdas curtas. Todo o lado externo do estípite, bordo da gálea e lado ventral do primeiro artículo do palpo labial com cerdas de ápice arqueado em forma de gancho.

Gnathanthidium pertence ao grupo de gêneros de Dianthidiini em que o arólio entre as garras é distinto no macho, porém ausente ou rudimentar na fêmea, como ocorre em Dicranthidium Moure \& Urban, 1975 e Anthidulum Michener, 1948. Este último distingue-se pelas carenas interalveolares muito fracas. Além disso, nestes dois gêneros a mandíbula da fêmea tem quatro dentes no bordo apical. O macho de Anthidulum tem no sexto tergo uma projeção mediana apical espiniforme, enquanto que em Dicranthidium e em Gnathanthidium o bordo do sexto tergo é liso, porém o sétimo tergo de Dicranthidium é peculiar com duas projecões digitiformes longas, amplamente separadas uma da outra e os esternos ornados com recortes e cerdas.

\section{Gnathanthidium sakagamii, sp.n.}

Figs 1-5

Caracteres diagnósticos. Fêmea com a cabeça quase negra, com áreas amarelas nas paroculares, nódoa amarela interalveolar (como no macho); terceiro ao quinto tergos com faixa amarela subapical, tergo distal emarginado no meio. Macho com mandíbula e clípeo em grande parte amarelos; paroculares inferiores amarelas; amarelo-ferrugíneo nos lados do mesoscuto, axilas e margem do escutelo (como na fêmea); tergos com faixas amarelas subapicais.

Holótipo macho. Tegumento predominante preto, cabeça com as seguintes áreas amarelas: quase todo lado externo das mandíbulas e no clípeo, este com o ápice e áreas látero-basais enegrecidas; paroculares inferiores, nódoa interalveolar grande com algo de ferrugíneo e unindo as carenas interalveolares, com o contorno mais ventral profundamente côncavo e o mais dorsal fracamente bi-sinuoso; amarelo-ferrugíneo na metade posterior do vértice e parte das pós-genas, no escapo, pedicelo e nos três flagelômeros basais. Asas tingidas com castanho escuro. Amarelo-ferrugíneo claro no terço ventral dos lobos pronotais incluindo a lâmina; amarelo-ferrugíneo formando estria larga nos lados do mesoscuto, unida à faixa basal amarela largamente interrompida no meio; axilas, metade basal do escutelo, tégulas e metade superior dos 
metepisternos amarelo-ferrugíneos; flancos do escutelo com nódoa translúcida castanha clara. Pernas em grande parte amarelo-ferrugíneas, nas anteriores e medianas só com a coxa, trocânter e base do fêmur enegrecidos, nas posteriores a área enegrecida bem longa na face anterior do fêmur̉, com nódoa amareloferrugínea na coxa. Primeiro ao sexto tergo com faixa amarela subapical, com margem translúcida esbranquiçada no primeiro, castanha e muito estreita nos demais; a faixa amarela mais estreita no segundo tergo, e o sétimo largamente amarelo na metade distal. Esternos com áreas castanhas, amarelo-ferrugíneas e amarelas, sem enegrecido.

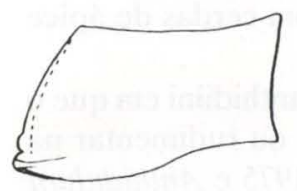

1

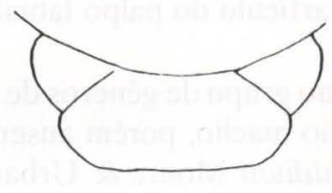

3

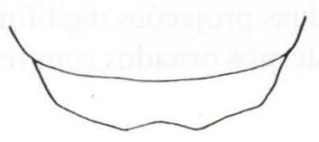

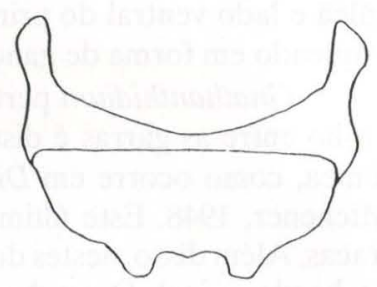

4

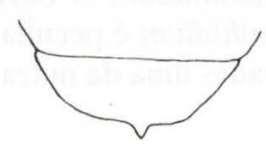

Figs 1-5. Gnathanthidium sakagamii, sp.n. e Fig. 6. Gnathanthidium ferrugineum, sp.n. (1) Mandibula da fêmea; (2) mandibula do macho; (3) escutelo e axilas; (4) sétimo tergo do macho; (5 e 6) ápice do sexto tergo da fêmea. Metade do aumento nos desenhos do escutelo e sexto tergo das fêmeas. A escala corresponde a um milímetro.

Pilosidade curta, castanha clara e lisa na cabeça exceto nas paroculares com pêlos brancos densamente plumosos, bordos do estípite e da gálea com pêlos finos eretos; branca e denso-plumosa no lado ventral do mesosoma, incluindo os flancos do propódeo, os lobos pronotais e áreas dorso-laterais do metanoto brancas e denso plumosa curtíssima, castanha clara e ereta no mesoscuto e escutelo, este com pêlos mais longos no ápice, voltados para cima. Pernas com pêlos curtos e sem formar franja. Nos esternos como nos mesepisternos porém mais esparsa e nos tergos curtíssima.

Disco do mesoscuto com pontuação muito densa e mais fina que a do escutelo; coxa e trocânter posteriores com projeção apical espiniforme, maior no trocânter.

Comprimento aproximado $7,17 \mathrm{~mm}$; comprimento da asa a partir do esclerito costal $6,09 \mathrm{~mm}$;largura da cabeça $2,64 \mathrm{~mm}$ e do metasoma $2,60 \mathrm{~mm}$; 
comprimento do olho $1,76 \mathrm{~mm}$; distância interorbital superior $1,68 \mathrm{~mm}$ e a inferior $1,22 \mathrm{~mm}$.

Alótipo fêmea. $\mathrm{O}$ tegumento difere do macho na cabeça e no metasoma. Cabeça com mandíbula, clípeo, fronte e partes mais dorsais das paroculares superiores e genas negros; nos cantos do clípeo, subapicalmente com nódoa arredondada castanho-amarelada; área interalveolar com grande nódoa amarela com algo de ferrugíneo como no macho; porção basal das paroculares, parte posterior do vértice e pós-genas amarelo-ferrugíneos. Pernas posteriores mais escuras que no macho, com área enegrecida na tíbia e os tarsômeros castanhoenegrecidos. Tergo basal, e do terceiro ao quinto com faixa subapical amarela, levemente bi-sinuosa no bordo proximal, no primeiro mais larga nos lados e no segundo somente nos flancos e mais estreita na parte dorsal; restante dos tergos e os esternos negros.

Pilosidade semelhante à do macho porém com cerdas finas de ponta arqueada nas genas junto ao hipóstoma; pilosidade muito curta e densa nas pernas; escopa esternal com pêlos lisos longos esbranquiçados.

Tergo distal emarginado no meio.

Comprimento aproximado $8,50 \mathrm{~mm}$; comprimento da asa a partir do esclerito costal $6,25 \mathrm{~mm}$; largura da cabeça $2,88 \mathrm{~mm}$ e do metasoma $2,84 \mathrm{~mm}$; comprimento do olho $2 \mathrm{~mm}$; distância interorbital superior $1,80 \mathrm{~mm}$ e a inferior $1,40 \mathrm{~mm}$.

Variações. Nos machos foi observada invasão maior ou menor de amarelo-ferrugíneo no primeiro tergo e na coxa posterior, tons mais escuros nos esternos, redução do amarelo no lado externo das mandíbulas e a faixa amarela do sexto tergo interrompida no meio. Nas fêmeas foram vistas modificações nas nódoas do clípeo, ora com a cor mais amarelada ora ausentes, e as faixas dos tergos com um toque ferrugíneo ou castanho.

Distribuição geográfica. BRASIL: Paraná, Santa Catarina e Rio Grande do Sul. Argentina: Misiones.

Holótipo macho com as seguintes etiquetas: /F.[oz do] Iguassu-PR Brasil-I-62 Sakagami \& Laroca [leg.]/Holótipo/Gnathanthidium sakagamii Urban, Urban det. 1993/. Alótipo fêmea com os mesmos dados do holótipo. Parátipos das seguintes localidades: com os mesmos dados do holótipo, um macho e uma fêmea; Santa Catarina, Seara (N. Teutônia), F. Plaumann leg., I-III/49 um macho; I-II/49 duas fêmeas; II/52 uma fêmea e dois machos; XI/55 cinco fêmeas e sete machos; XII/55 duas fêmeas; I/57 uma fêmea e três machos. Rio Grande do Sul, Caçapava do Sul, Guarita, C. Schindwein leg.; 21-XII-91 um macho e uma fêmea. ARGENTINA, Misiones, Bemberg, Hayward, Willink e H. Golbach leg.; 14-30/III/45 um macho. Todos depositados na Coleção de Entomologia Pe. J.S. Moure, Departamento de Zoologia da Universidade Federal do Paraná.

Esta espécie é dedicada ao Prof. Dr. Shoichi F. Sakagami pelos seus trabalhos em Entomologia. 


\section{Gnathanthidium ferrugineum, sp.n.}

Fig. 6

Características diagnósticas. Fêmea com o tegumento da cabeça em grande parte amarelo-ferrugíneo com áreas negras junto aos ocelos e perto das antenas; pontuação do disco do mesoscuto grossa como a do escutelo; tergo distal com projeção mediana espiniforme; terceiro e quarto tergos com faixa amarela subapical mais larga no meio. Macho desconhecido.

Holótipo fêmea. Tegumento da cabeça quase todo amarelo-ferrugíneo, com as mandíbulas castanho-escuras, labro e ápice do clípeo pretos; uma estria larga castanha enegrecida pouco acima dos alvéolos antenais e abaixo dos mesmos, área ocelar preta, hipóstoma castanho; antenas amarelo-ferrugíneas nos artículos basais até o quinto flagelômero por baixo e até o terceiro por cima, no mais castanho claro. Mesosoma preto ventralmente, em grande parte do mesoscuto, do escutelo e no propódeo; lobos pronotais amarelo-ferrugíneos, flancos do pronoto com nódoa ferrugíneo-acastanhada; mesoscuto com estria lateral prolongada anteriormente em faixa basal amarelo-ferrugínea, largamente interrompida no meio; axilas e fina orla posterior no escutelo amarelas. Pernas com os artículos basais enegrecidos até a base do fêmur, no restante das anteriores amarelo-ferrugíneo, nas medianas com parte do fêmur, toda a tíbia e parte basal do basitarso amarelo-ferrugíneo e restante dos tarsômeros castanhos, e nas posteriores com pouco amarelo-ferrugíneo, predominando o castanho. Asas tingidas com castanho. Tergo basal com larga faixa amarela subapical, mais larga nos flancos; segundo tergo com uma nódoa amarela a cada lado, visível ventralmente; terceiro e quarto com faixa amarela subapical larga e levemente angulosa no meio, estreitando para os lados e alargando um pouco ventralmente, demais áreas castanho-enegrecidas.

Pilosidade muito curta, branca na cabeça incluindo o vértice, os pêlos alongados e plumosos no meio das paroculares; genas e estípite com cerdas ocráceas claras de ápice em gancho (demais peças bucais não foram examinadas); curtíssima branca e lisa no mesoscuto e no escutelo; branca, curta e denso-plumosa no lado ventral do mesosoma; branca, muito curta e densa nas pernas; escopa esternal levemente amarelada; nos tergos branca curta e esparsa.

Tergo distal com projeção mediana espiniforme e emarginação aos lados.

Comprimento aproximado $7,17 \mathrm{~mm}$; comprimento da asa a partir do esclerito costal $5,08 \mathrm{~mm}$; largura da cabeça $2,18 \mathrm{~mm}$ e do metasoma $2,04 \mathrm{~mm}$; comprimento do olho $1,60 \mathrm{~mm}$; distância interorbital superior $1,44 \mathrm{~mm}$ e a inferior $1,14 \mathrm{~mm}$.

Distribuição geográfica. ARGENTINA, Tucumán.

Holótipo fêmea com as etiquetas: /S. [an] P. [edro] Colalao Arg. [entina] Prov.Tucuman I.1953 F.H. Walz [leg.]/Holótipo/Gnathanthidium ferrugineum Urban, Urban det. 1993/. Depositado na Coleção de Entomologia Pe. J.S. Moure, Departamento de Zoologia da Universidade Federal do Paraná. 
AGRADECIMENTOS. A autora agradece ao Prof. Dr. Pe. Jesus S. Moure pela sugestão do nome dado ao gênero, que se refere às mandibulas das fêmeas.

\section{REFERÊNCIAS BIBLIOGRÁFICAS}

GRISWOLD, T.L. \& C.D. MICHENER. 1988. Taxonomic observations on Anthidiini of the Western Hemisphere (Hymenoptera, Megachilidae). Jour. Kansas Ent. Soc. 61 (1): 22-45.

MICHENER, C.D. 1948. The generic classification of the Anthidiinae bees (Hymenoptera, Megachilidae). Amer. Mus. Novit. 1381: 1-29.

MOURE, J.S. 1965. New Placements for some species of Paranthidium (Hymenoptera,Apoidea). Proc. Ent. Soc. Wash. 67 (1): 29-31.

MOURE, J.S. \& D. URBAN. 1975. Dicranthidium novo subgênero de Hypanthidioides Moure, 1947. Rev. Brasil. Biol. 55: 837-842.

Recebido em 02.VII.1993; aceito em 24.IX.1993. 